\title{
Relevance of the P \& O MPPT Technique in an Original PV-Powered Water Pumping Application
}

\author{
Said Aissou ${ }^{1}$, Sébastien Jacques ${ }^{2,3}$, Zahra Mokrani ${ }^{1}$, Djamila Rekioua ${ }^{1}$, Toufik Rekioua ${ }^{1}$ and Abdeldjalil Ouahabi ${ }^{2}$ \\ 1. Electrical Engineering Department, University of Bejaia, Bejaia 06000, Algeria \\ 2. Electronics and Energy Department, Polytech Tours, University of Tours, Tours 37200, France \\ 3. Research Group on Materials, Microelectronics, Acoustics \& Nanotechnology, University of Tours, Tours 37200, France
}

Received: September 21, 2015 / Accepted: October 10, 2015 / Published: November 30, 2015.

\begin{abstract}
Many papers exploiting the various MPPT (maximum power point tracking) techniques in PV (photovoltaic) applications, from the simple to the most complicated, can be found in literature. However, these techniques may not always be easy to implement in industrial applications. The main challenge of this paper is to model and implement the P \& O (perturb and observe) algorithm in a low-cost PV-powered pumping system. To that end, a comparative investigation of the performance characteristics of the most popular MPPT methods, such as FOCV (fractional open circuit voltage), FSCC (fractional short circuit current), FLC (fuzzy logic control), ANN (artificial neural network) and INC (incremental conductance) is presented. This analysis is helpful to highlight the relevance of the P \& O technique taking better account of complexity, difficulty of implementation and cost considerations in water pumping applications. The targeted PV-powered pumping system is based on a single-phase induction motor supplied by a three-phase inverter controlled by the DTC (direct torque control) technique. This stand-alone PV system is dedicated to water pumping, especially in rural areas that have no access to national grids but have sufficient amount of solar radiation. Simulation modeling (Matlab/Simulink) and experimental results are presented to demonstrate the relevance of the system.
\end{abstract}

Key words: DC-DC power converter, MPPT algorithms, P \& O, stand-alone PV-powered water pumping system.

\section{Introduction}

Over the years, photovoltaics has proven to be an attractive environmentally friendly energy source since it has had key implications, both in economic and ecological terms $[1,2]$. A large number of serious studies have recently shown that, as a consequence of its very strong growth in the last decade, PV (photovoltaic) energy is now on the way to becoming a mature technology [3]. The world's total installed solar PV electricity generation capacity has been predicted to double, from about $100 \mathrm{GW}$ in 2012 to $200 \mathrm{GW}$ in 2015 [4, 5].

Stand-alone PV systems always attract considerable interest in a wide range of applications:

Corresponding author: Sébastien Jacques, associate professor, research fields: conversion and management of electrical energy. E-mail: sebastien.jacques@univ-tours.fr. water-pumping installations (especially, automatic irrigation systems), industry, telecommunications and public services, health (for instance, for an emergency health clinic), residential and free time [6]. However, in such applications, low conversion efficiency can typically be pointed out, depending on weather conditions (irradiance, ambient temperature).

A solution for increasing the output power of any PV system consists in tracking its MPP (maximum power point). At that point, the PV system operates at maximum efficiency as it produces its maximum output power. Numerous papers have also emphasized the crucial role of MPPT (MPP tracking) system and particularly its control strategies to maintain the PV array's operating point at its MPP [7].

Currently, there are many MPPT algorithms that have been developed to improve the cost-effectiveness 
of PV systems. Most of these MPPT control techniques have been reported in the literature. The following non-exhaustive list presents the commonly used techniques: fractional open circuit voltage, fractional short circuit current, fuzzy logic, neuronal network, hill climbing, perturb and observe or incremental conductance. Some users may be a little confused by selecting a suitable MPPT method aimed at a novel application. A few papers have recently published and suggested ways of dealing with these issues [8-11].

This paper serves several purposes. First of all, the objective is to get a better understanding of the main MPPT techniques reported in the literature. In particular, a comparison is proposed based on the following criteria: targeted application, control strategy, control variable, circuitry, complexity level converter used and cost. Then, the ultimate challenge is to select the best MPPT algorithm and implement it to control a cost-effectiveness PV-powered pumping system $(35 \mathrm{l} / \mathrm{min})$. It is important to note that, water pumping is one of the most important applications of photovoltaics particularly in rural areas, because of a considerable amount of solar radiation and for reasons of electrical grid which is most often inaccessible. The PV-powered pumping system described in this article is based on a centrifugal pump which is the most used in low head applications [12]. A $370 \mathrm{~W}$ single-phase induction motor is used to drive the centrifugal pump. A DC-DC converter using MPPT controlling in association with an inverter is used to control the induction motor.

First of all, the present manuscript introduces the functioning of the PV-powered pumping system. Then, the typical MPPT techniques are highlighted. The literature review will help to choose the best method to be implemented in the PV-powered pumping system. The last part of the paper is dedicated to the implementation of the MPPT technique. A discussion is proposed to point out the relevance of the study.

\section{Review of the Background and Motivations}

\subsection{Description of the Targeted Application}

Many recent studies have highlighted regularly that PV-powered pumping systems require developing innovative approaches and techniques to increase their efficiency, cost-effectiveness and reliability.

Fig. 1 illustrates the block diagram of the low cost stand-alone PV-powered system dedicated to water pumping applications, especially in insulated or mountainous locations and in temporary installations because of a natural disaster.

This system is based on the control of $370 \mathrm{~W}$ single-phase induction motor (AC motor) using the DTC (direct torque control) technique. This technique describes the way in which the control of torque and speed are directly based on the electromagnetic state of the motor in comparison with PWM drives which use input frequency and voltage. There are many benefits of the DTC control method: torque response, accurate torque control at low frequencies, torque repeatability, motor static and dynamic speed accuracy. It is important to note that, the IM (induction motor) offers the advantage of being supplied with single-phase. It is commonly used in low power rating applications, in domestic as well as industrial use.

The photovoltaic generator is composed of six $80 \mathrm{Wp}$ solar panels (SUNTECH STPO80S-12/BB PV module). A three-phase inverter composed of IGBTs (insulated gate bipolar transistors) is used to convert the direct current of the PV generator into an

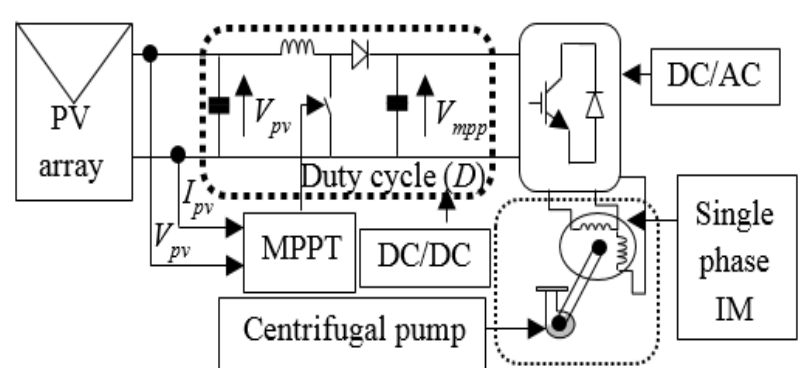

Fig. 1 General architecture of the PV-powered water pumping application. 
alternating current that is necessary to drive the $\mathrm{AC}$ motor of the centrifugal pump ( $35 \mathrm{l} / \mathrm{min})$. A DC-DC converter (boost converter) that incorporates the MPPT function is used to step up the voltage of the $\mathrm{PV}$ array to the input voltage of the inverter. One key element of this standalone system is the MPPT algorithm that is embedded in the DC-DC converter to maximize the power generated by the PV modules independently of temperature and the amount of solar irradiation.

This article focuses on the MPPT function that is of primary importance to increase the efficiency of the PV system.

\subsection{Modeling and Characterization of the $P V$ Generator}

Many mathematical models have been reported in literature to extract the I-V curve of a PV generator [13]. The features of this PV generator is usually translated either to an equivalent circuit of one-diode model or an equivalent circuit of two-diode model containing a photocurrent source, a diode or two diodes, a shunt resistance $\left(R_{s h}\right)$ and a series resistance $\left(R_{s}\right)$ in the load branch [14]. These models usually give the cell current as a nonlinear implicit function requiring a nonlinear numerical technique such as the Newton-Raphson method to solve the equation. In this work, the one-diode model is selected (Fig. 2).

To model the I-V curve of a PV cell, the photovoltaic current $\left(I_{P V}\right)$ can be calculated using Eqs. (1) and (2) [15-17]. In these equations, $I_{p h}, I_{d}, I_{R s h}$, $K, I_{0}, N_{s}, A, q$, and $T_{j}$ represent the photo-generated current, diode-current, shunt-leakage current, Boltzmann's constant $(\mathrm{J} / \mathrm{K})$, diode reverse bias saturation current, number of PV cells associated in

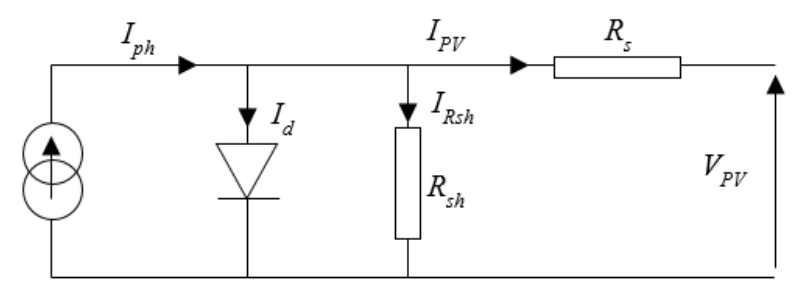

Fig. 2 One-diode model of a PV generator. serial, ideality factor of the P-N junction, electron charge (C), and junction temperature of the solar cell, respectively.

$$
\begin{gathered}
I_{P V}=I_{p h}-I_{d}-I_{R s h} \\
I_{P V}=I_{p h}-I_{0} \cdot\left[\exp \left(\frac{q \cdot\left(V_{P V}+R_{s} \cdot I_{P V}\right)}{A \cdot N_{s} \cdot K \cdot T_{j}}\right)-1\right]-\frac{V_{P V}+R_{s} \cdot I_{P V}}{R_{s h}}
\end{gathered}
$$

Fig. 3 shows the power-voltage characteristic that can be extracted for various temperature and irradiance values using the equations described above.

\subsection{Main Features of the DC-DC Converter}

Fig. 4 shows the electrical schematic of the DC-DC boost converter.

The aim of this converter is to extract the maximum power from the PV array. So, it acts as an interface between the PV array and the load, allowing the follow-up of the MPP [18-21]. The DC/DC conversion process is similar to the transformer one when it is used as an impedance adaptor, except that, in

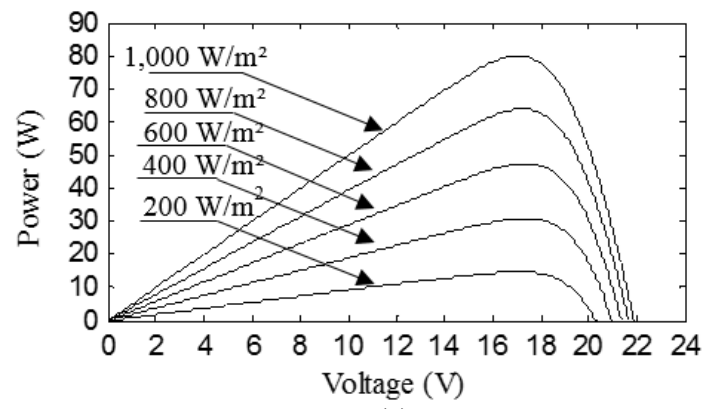

(a)

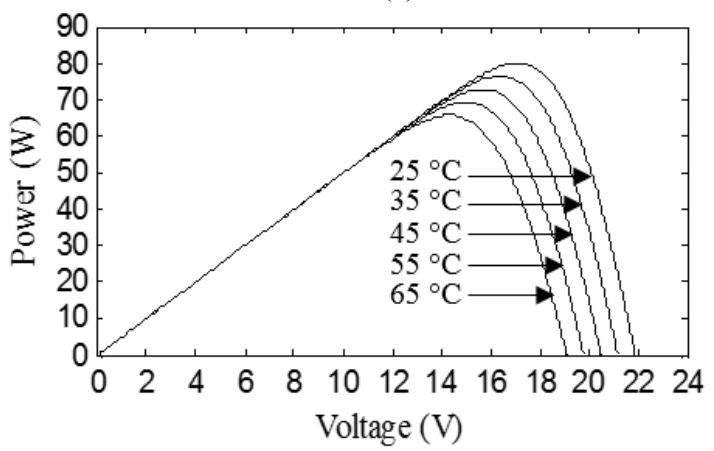

(b)

Fig. 3 Power-voltage curve of the SUNTECH STPO80S-12/BB PV module (Matlab simulation results) for various irradiance (a) and temperature (b) values. 


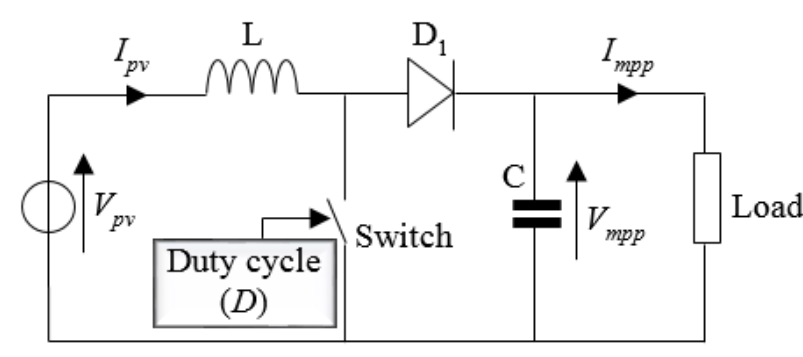

Fig. 4 Electrical schematic of the DC/DC boost converter.

converter the adaptation parameter is not the turns ratio between the secondary and primary ones, but the duty cycle $(D)$, which can be governed electronically.

Eqs. (3) and (4) give voltage and current equations of the DC-DC converter (voltage and current at MPP).

$$
\begin{aligned}
& V_{m p p}=\frac{1}{1-D} V_{P V} \\
& I_{m p p}=(1-D) I_{P V}
\end{aligned}
$$

\subsection{Single-Phase Induction Motor Modeling}

Regarding the targeted application, a SPIM (single phase induction motor) is used to drive a centrifugal pump. Although this kind of motor is not widely accepted in literature, it can be an excellent choice due to consideration of cost, simplicity of control and operation [22-25]. As can be seen in Fig. 5, this motor is composed of two windings, a primary one and an auxiliary one, and a start capacitor [26]. In this application, the start capacitor is removed. The SPIM is supplied by a three-phase inverter that is controlled using the DTC (direct torque control) technique. Eqs. (5)-(8) give its stator voltage, flux and torque equations in a stationary reference frame $[19,26]$.

$$
\begin{gathered}
\left\{\begin{array}{l}
V_{s \alpha}=R_{s \alpha} i_{s \alpha}+\frac{\mathrm{d} \Phi_{s \alpha}}{\mathrm{d} t} \\
V_{s \beta}=R_{s \beta} i_{s \beta}+\frac{\mathrm{d} \Phi_{s \beta}}{\mathrm{d} t}
\end{array}\right. \\
\left\{\begin{array}{l}
0=R_{r} i_{r \alpha}+\frac{\mathrm{d} \Phi_{r \alpha}}{\mathrm{d} t}+\omega \Phi_{r \beta} \\
0=R_{r} i_{r \beta}+\frac{\mathrm{d} \Phi_{r \beta}}{\mathrm{d} t}-\omega \Phi_{r \alpha}
\end{array}\right. \\
\left\{\begin{array}{l}
\Phi_{s \alpha}=L_{s} i_{s \alpha}+M i_{r \beta} \\
\Phi_{s \beta}=M i_{s \beta}+L_{r} i_{s \beta}
\end{array}\right.
\end{gathered}
$$

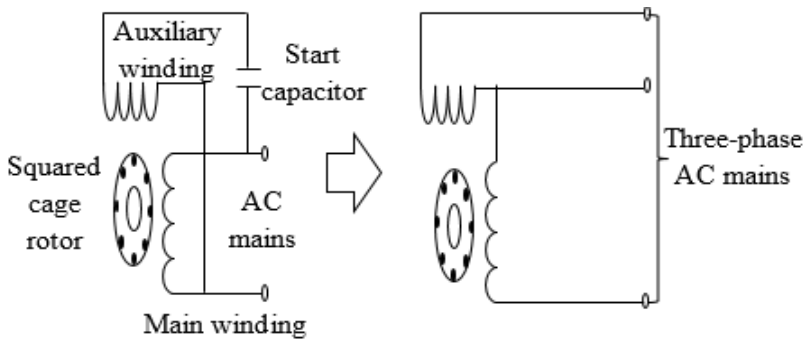

Fig. 5 Outline schematic of the SPIM.

$$
\Gamma_{e}=\frac{P}{2} \frac{M}{L_{r}}\left(\Phi_{r \beta} i_{s \alpha}-\Phi_{r \alpha} i_{s \beta}\right)
$$

In the equations described above, $V_{s \alpha}$ and $V_{s \beta}$ are the stator voltages ( $\alpha-\beta$ axes), respectively. $i_{s \alpha}, i_{r \alpha}$ and $i_{r \beta}$ are the stator and rotor currents ( $\alpha-\beta$ axes), respectively. $R_{s \alpha}$ corresponds to the stator resistance ( $\alpha-\beta$ axes). $R_{r}$ is the rotor resistance. $L_{s}$ and $L_{r}$ are the stator and rotor self-inductances, respectively. $M$ is the mutual inductance. $P$ is the number of pole pairs of the machine. $\Gamma_{e}$ is the electromagnetic torque.

\subsection{Modeling of the Centrifugal Pump}

The centrifugal pump load torque $\left(\Gamma_{r}\right)$ is proportional to the square of the rotor speed $(\Omega)$. Eq. (9) gives its mathematical equation, where $k_{c}$ is the proportionality constant [27-29].

$$
\Gamma_{r}=k_{c} \cdot \Omega^{2}
$$

The $H-Q$ characteristic of the pipe network is expressed in Eq. (10), where $H, Q, H_{g}, \Psi$ are the total head, the flow rate, geometrical head and the constant that includes the length and diameter of the pipe and the various loss coefficients, respectively. The $\mathrm{H}$-parameter can be considered as the total opposing head of the system that must be overcome for the fluid to be pumped from the lower to the upper reservoir.

$$
H=H_{g}+\Psi Q^{2}
$$

\section{Comprehensive Overview of MPPT Techniques}

\subsection{Motivations}

There is a vast literature on the question of MPPT techniques' development and implementation. The 
MPPT algorithms can be classified according to the level of difficulty of their implementation. We propose here to classify these algorithms into three categories: simple, medium and complex. In the following sections of the article, two poplar techniques in each category are analyzed. In particular, the robustness of each technique is discussed. The aim of this section is to choose the best MPPT algorithm that fits the application requirements.

\subsection{Simple Category of MPPT Algorithms}

\subsubsection{FOCV (Fractional Open Circuit Voltage)}

As described in Eq. (11), the FOCV MPPT algorithm is based on the fact that, the PV array voltage $\left(V_{m p p}\right)$ that corresponds to the MPP exhibits a linear dependence with respect to array open circuit voltage $\left(V_{o c}\right)$ for different irradiation and temperature levels [8-10]. In this equation, the $K_{o c}$-parameter varies from 0.78 to 0.92 .

$$
V_{m p p} \approx K_{o c} \cdot V_{o c}
$$

Fig. 6 describes the flowchart of FOCV operation.

\subsubsection{FSCC (Fractional Short Circuit Current)}

As described in Eq. (12), the FSCC MPPT algorithm is based on the fact that there is a linear relationship between the current at MPP $\left(I_{m p p}\right)$ and the short circuit current $\left(I_{S C}\right)$ [8-10]. In this equation, the $K_{S C}$-parameter varies typically from 0.85 to 0.95 .

$$
I_{m p p} \approx K_{S C} \cdot I_{S C}
$$

Fig. 7 describes the flowchart of FSCC operation. The FSCC MPPT technique can easily be implemented with current sensor. The main drawback of using this MPPT is the periodic loss of power while measuring the short circuit current.

\subsection{Medium Category of MPPT Algorithms}

\subsubsection{P \& O (Perturb and Observe)}

The $\mathrm{P} \& \mathrm{O}$ MPPT method is one of the most popular methods [30]. Its flowchart of operation is presented in Fig. 8.

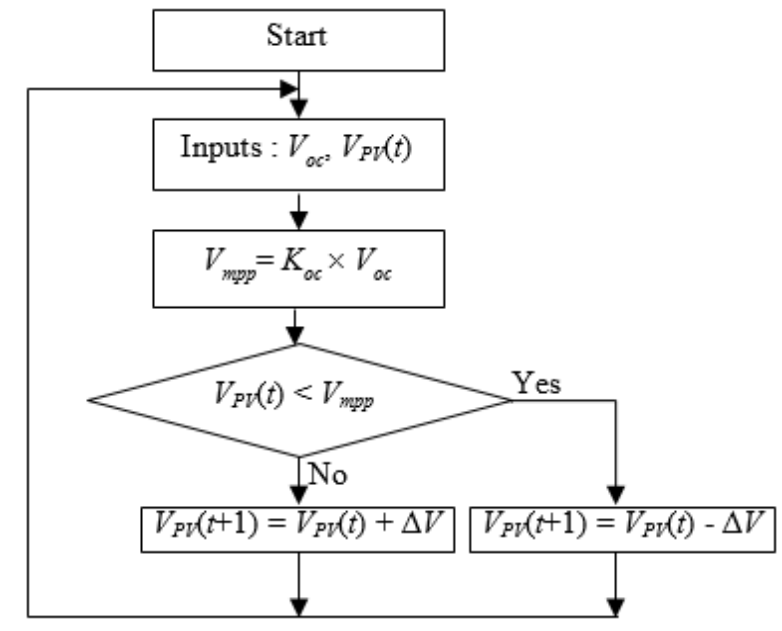

Fig. 6 Flowchart of the FOCV MPPT algorithm.

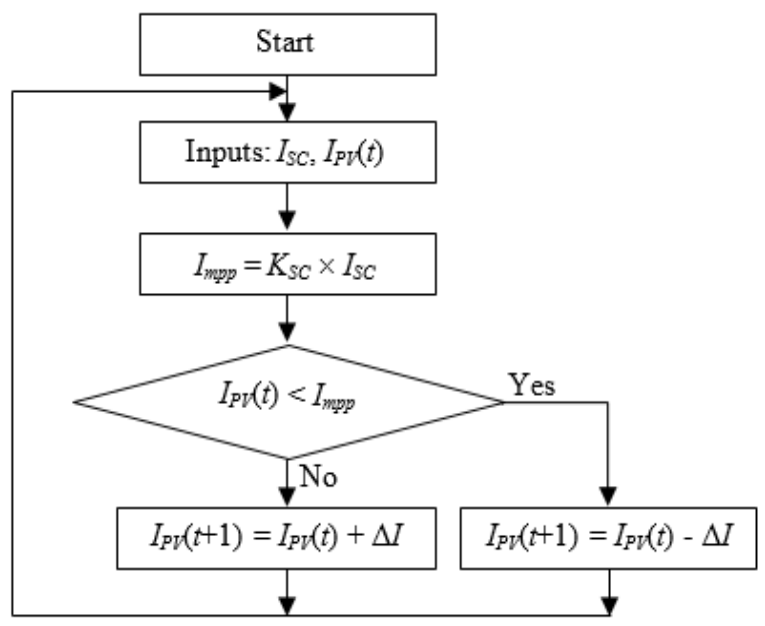

Fig. 7 Flowchart of the FSCC MPPT algorithm.

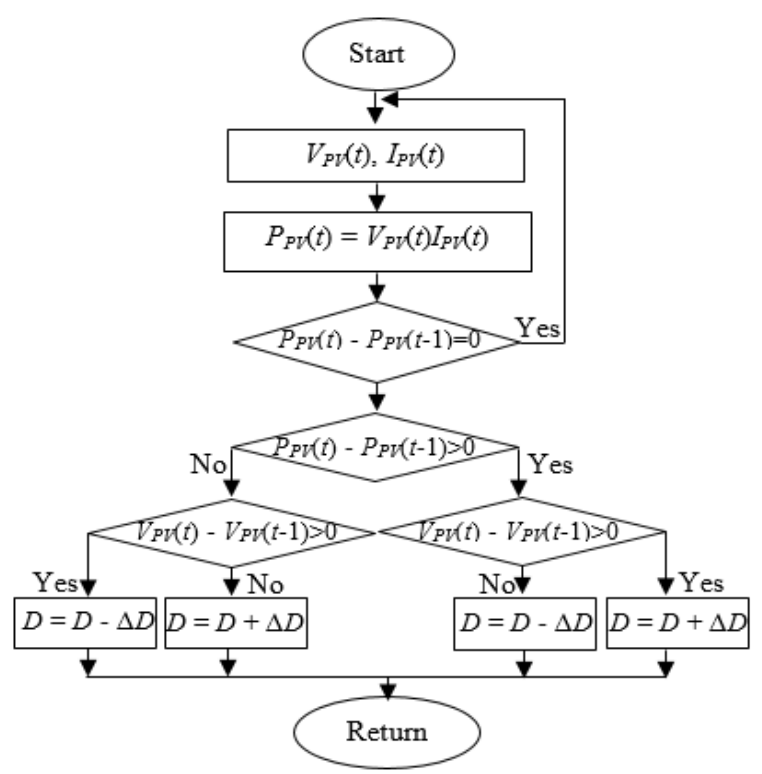

Fig. 8 Flowchart of the P \& O MPPT algorithm. 
As can be seen in Fig. 9, the voltage is perturbed in one direction through the control of the duty cycle of the switch in the DC-DC converter. If the power continues to increase, then the algorithm keeps on perturbing in the same direction. If the new power is less than the previous one, it will perturb the system in the opposite direction. However, even if the stable condition is reached, the algorithm oscillates around the MPP $[10,11,31,32]$.

This MPPT algorithm is very popular because it helps to fix a reference voltage across the PV module. This reference voltage corresponds to the peak value. A PI (proportional integral) controller is typically used to transfer the operating point of the solar panel to the reference voltage. However, the technique is not able to track the MPP in fast changing weather conditions.

\subsubsection{INC (Incremental Conductance)}

The incremental conductance MPPT algorithm perturbs the voltage in one direction and evaluates the sign of the derivative of the power $(d P / d V)$. If the sign is negative, the algorithm decreases the value of the duty cycle; otherwise, the duty cycle is increased.

A flowchart of operation is depicted in Fig. 10 $[7,10,12,33]$.

This MPPT technique presents two main drawbacks as reported in the literature. First of all, the power response shows ripples. Secondly, the time response is not negligible. Nevertheless, it is possible to change the duty cycle of the switch used in the DC-DC converter to improve the time response of the system.

\subsection{Intelligent Category of MPPT Algorithms}

\subsubsection{FLC (Fuzzy Logic Control)}

It is recognized by the scientific community that, the FLC MPPT algorithm is one of the most intelligent technique. It has many advantages such as fast response, less fluctuation in the case of rapid changes in temperature and irradiance. The FLC method is based on the calculation of two parameters as expressed in Eqs. (13) and (14): error $(E)$ and change of error $\left(C_{E}\right)$ [20, 21, 34-36].

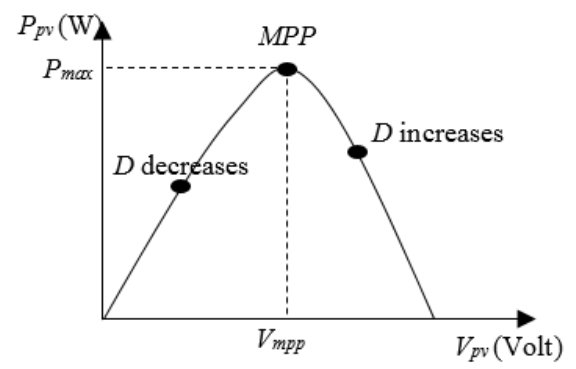

Fig. 9 Operation principle of the P \& O MPPT algorithm.

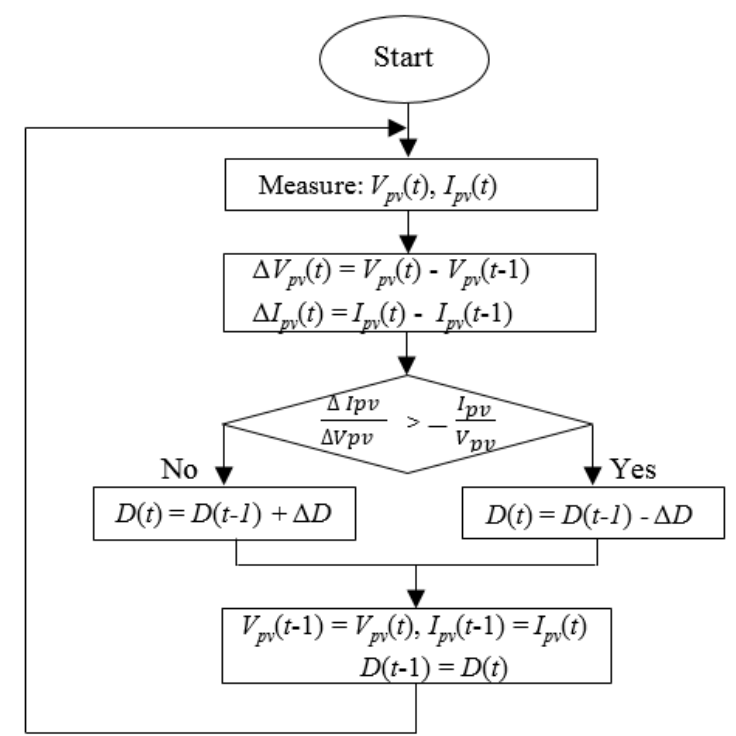

Fig. 10 Flowchart of the INC MPPT algorithm.

$$
\begin{gathered}
E(t)=\frac{P(t)-P(t-1)}{V(t)-V(t-1)} \\
C_{E}(t)=E(t)-E(t-1)
\end{gathered}
$$

Fig. 11 shows the block diagram of the FLC technique. It is composed of three stages: fuzzification, inference and defuzzification.

The fuzzification stage consists in converting the numerical input variables (error and change of error) to fuzzy inputs. As can be seen in Fig. 12, these fuzzy inputs correspond to linguistic variables: NB (negative big), NS (negative small), ZE (zero equal), PS

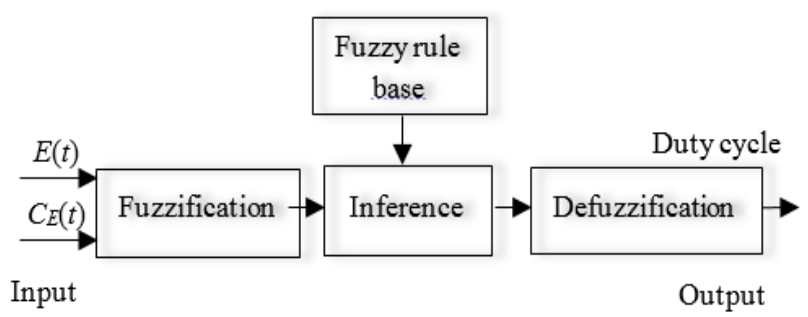

Fig. 11 Block diagram of the FLC MPPT technique. 


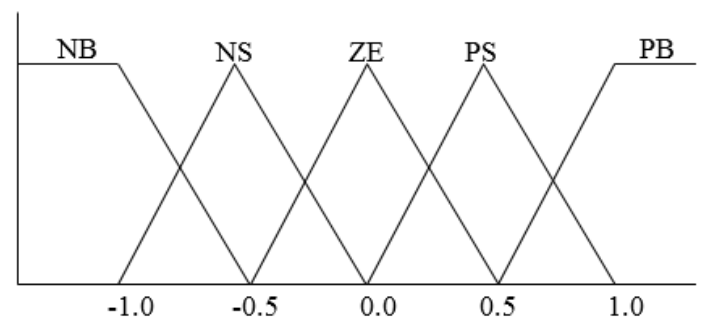

Fig. 12 Membership functions of the inputs and outputs of the FLC MPPT method.

(positive small) and PB (positive big). It is necessary to have some rules that are applied in the inference block. These rules are arranged in a fuzzy matrix (Table 1) [25]. Finally, the defuzzification process consists in converting the output subset to numerical variables [21, 34].

\subsubsection{ANN (Artificial Neural Network)}

The ANN is another intelligent MPPT technique that consists in estimating at any time the required optimal duty cycle $(D)$. Fig. 13 shows the block diagram of the ANN method.

It is composed of an input layer (PV power), a pattern layer, a summation layer and an output layer (duty cycle that is necessary to control the DC-DC converter to track the MPP [37-39]. Many papers have highlighted that, the ANN algorithm is a result of a compromise between rapidity in transient regime and stability in steady-state, even if its effectiveness has been proven and particularly in varying environmental conditions.

\subsection{Choice of the Best MPPT Technique for the Targeted Application}

The aim of this section is to choose the most appropriate MPPT algorithm that fits the water pumping system requirements, according to the criteria of Table $2[8-10,20,21,34-41]$. It is important to note that, the water pumping system must be simple to design and implement in a practical way, reliable and be the most cost-effective solution. The PV-powered system must use a power based MPPT method based on iterative algorithms to track continuously the MPP through the current and voltage
Table 1 Fuzzy rules.

\begin{tabular}{|c|c|c|c|c|c|}
\hline $\mathrm{E}$ & NB & NS & $\mathrm{ZE}$ & PS & PB \\
\hline $\mathrm{NB}$ & $\mathrm{ZE}$ & $\mathrm{ZE}$ & NB & NB & $\mathrm{NB}$ \\
\hline NS & $\mathrm{ZE}$ & $\mathrm{ZE}$ & NS & NS & NS \\
\hline ZE & NS & $\mathrm{ZE}$ & ZE & $\mathrm{ZE}$ & PS \\
\hline PS & PS & PS & PS & ZE & ZE \\
\hline PB & PB & PB & PB & ZE & ZE \\
\hline
\end{tabular}

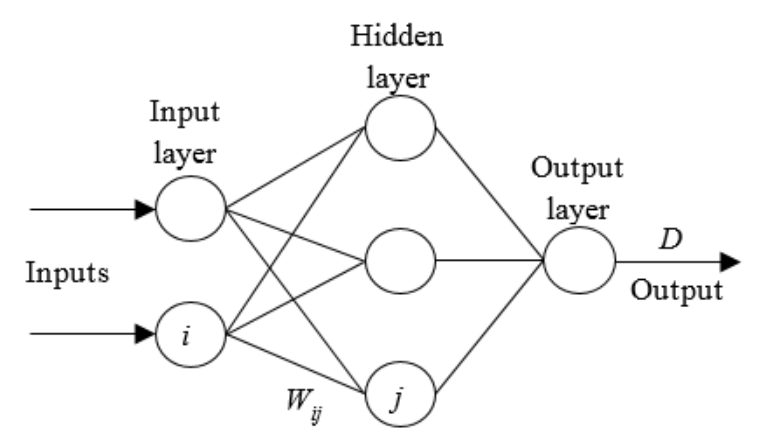

Fig. 13 ANN MPPT modeling.

measurements of the PV array. Therefore, from Table 2, two methods may be chosen: INC and P \& O. both algorithms are examples of "hill climbing" methods that can find the local maximum of the power curve for the operating condition of the PV array, and so provide a true maximum power point.

Even if the INC algorithm is able to track changing conditions more rapidly than the P \& O method, it is not chosen because it requires more computation in the controller. The $\mathrm{P} \& \mathrm{O}$ algorithm is the best solution according to the application requirements. The next section of the paper deals with the implementation of this technique.

\section{Experimental Results and Discussion}

\subsection{Test Bench Set Up}

Fig. 14 shows the experimental test bench of the PV pumping system.

The current and voltage of the PV array were measured using the LA25-P and LV25-P hall effect sensors, respectively. Considering the experimental test procedure flexibility and ease of programming, a dspace DS1104 real-time controller was used for control and data acquisition. This board is composed of a Motorola power PC (603 e model) that operates at 
Table 2 MPPT techniques' sum up.

\begin{tabular}{llllllllll}
\hline $\begin{array}{l}\text { MPPT } \\
\text { Technique }\end{array}$ & $\begin{array}{l}\text { Variable } \\
\text { control }\end{array}$ & $\begin{array}{l}\text { Control } \\
\text { strategy }\end{array}$ & Cost & Efficiency (\%) & Application & $\begin{array}{l}\text { Complexity } \\
\text { level }\end{array}$ & $\begin{array}{l}\text { Circuitry } \\
\text { (A/D) }\end{array}$ & $\begin{array}{l}\text { Tuning } \\
\text { parameter }\end{array}$ & $\begin{array}{l}\text { Converter } \\
\text { used }\end{array}$ \\
\hline FOCV & V or I & Incm & Low & About 92 & Standalone & Low & Both & Yes & DC/DC \\
FSCC & V or I & Incm & Low & About 96 & Standalone & Low & Both & Yes & DC/DC \\
FLC & V or I & Intm & Medium & About 98 & Both & High & D & Yes & Both \\
ANN & V or I & Intm & Medium & About 98 & Both & High & D & Yes & Both \\
P \& O & V and I & Smc & Low & Lower than 90 & Standalone & Low & Both & No & DC/DC \\
INC & V and I & Smc & Low & Lower than 90 & Standalone & Medium & Both & No & DC/DC \\
\hline
\end{tabular}

Note: Incm = indirect control method, Smc = sampling method, Intm = intelligent control method.

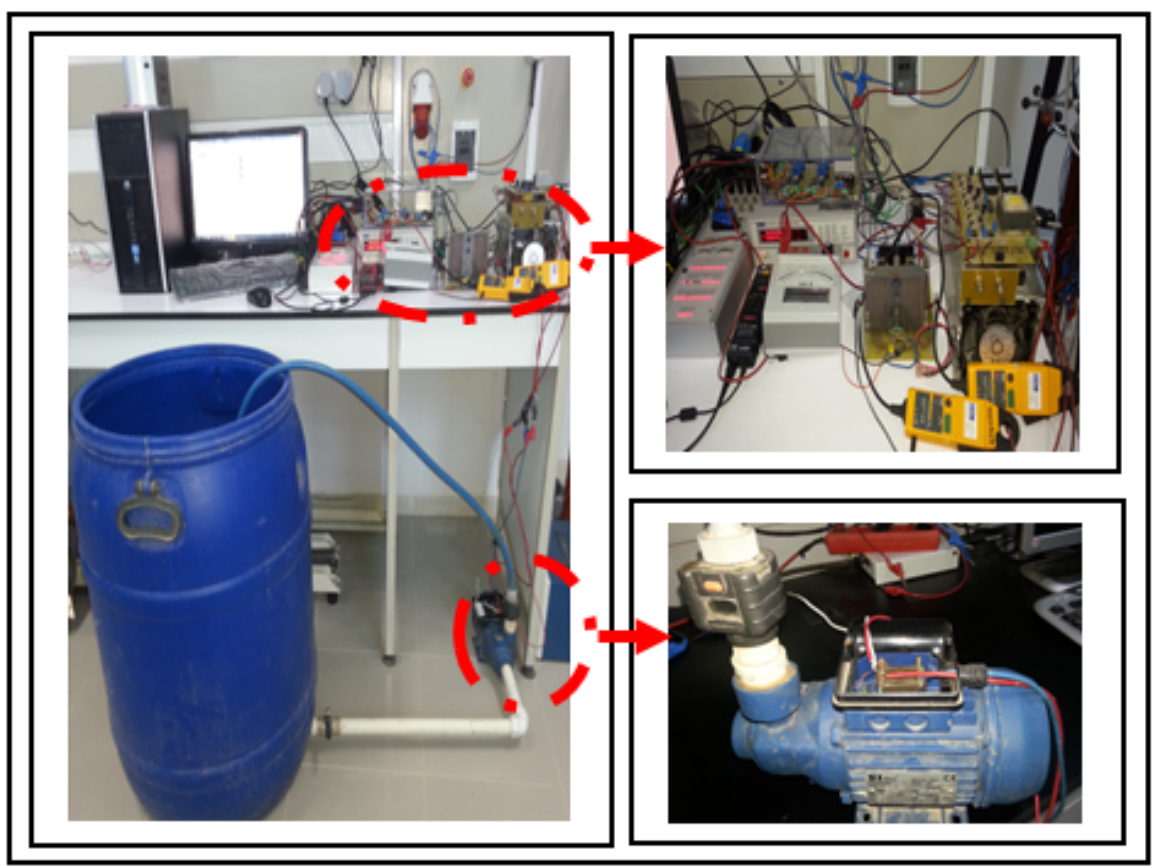

Fig. 14 Experimental test bench set up.

$250 \mathrm{MHz}$ and a DSP (digital signal processor) card (TMS320F240-20 MHz). All the experimental data are recorded using Matlab.

\subsection{Simulation and Experimental Test Results}

The whole PV-powered pumping system that uses the P \& O MPPT algorithm was modeled using the Matlab/Simulink environment. Many simulations were performed in constant and variable irradiance and ambient temperature (these values can typically be measured in Bejaia in July). These simulations were validated using the experimental measurements performed in the same conditions.

For example, two sets of irradiance and ambient temperature were tested simultaneously: $\left(790 \mathrm{~W} \cdot \mathrm{m}^{-2}\right.$; $\left.28.4^{\circ} \mathrm{C}\right)$ and $\left(650 \mathrm{~W} \cdot \mathrm{m}^{-2} ; 28.9^{\circ} \mathrm{C}\right)$. The simulation and experimental test results can be depicted in Fig. 15.

The simulation and experimental test results exhibit that, in the same conditions of step size and perturbation frequency, in the first $10 \mathrm{~s}$, the MPPT controller moves to the optimal duty cycle in $0.08 \mathrm{~s}$. One can notice that, the system response oscillates at the optimal value of the duty cycle due to the choice of the MPPT method ( $\mathrm{P} \& \mathrm{O})$. The power response oscillates at the MPP. Its mean value is equal to $365 \mathrm{~W}$. At that point, the mean voltage and current are about $177 \mathrm{~V}$ and $2.06 \mathrm{~A}$, respectively. In the last $10 \mathrm{~s}$, the MPPT controller reaches its optimal duty cycle in $0.08 \mathrm{~s}$. 

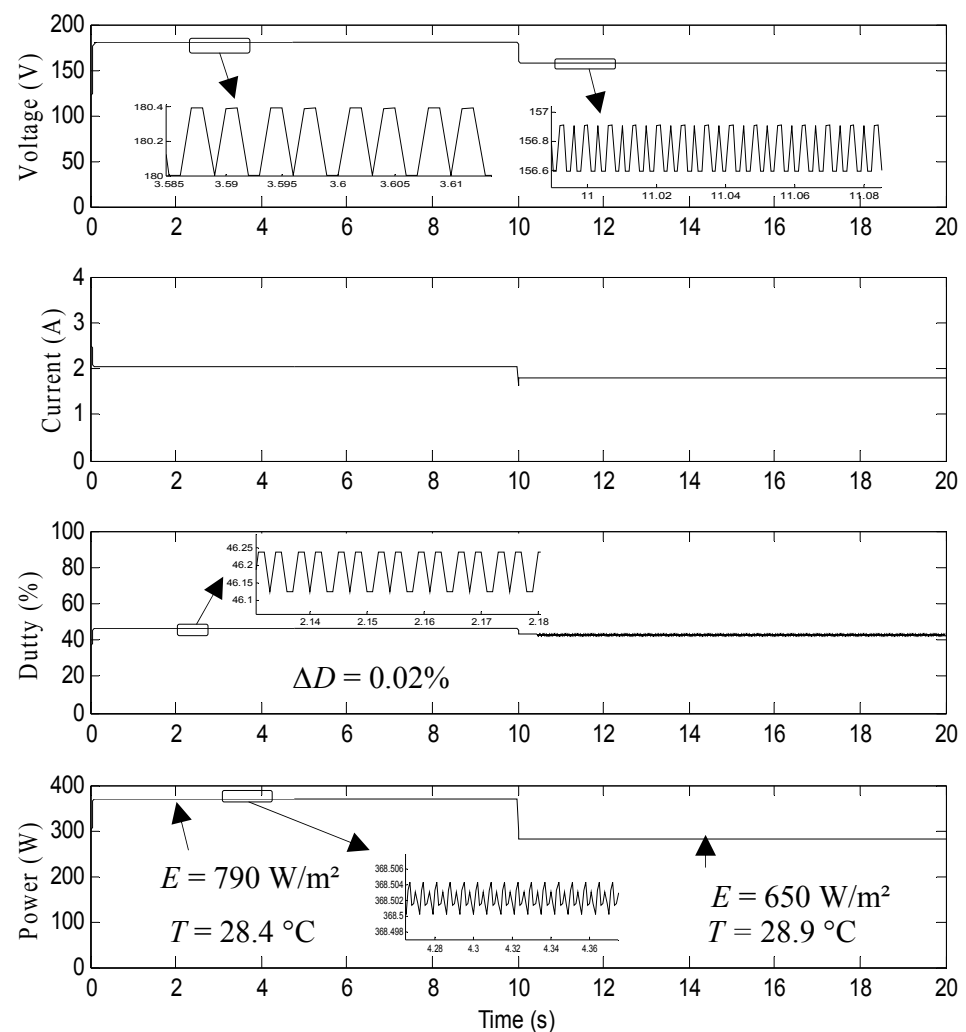

(a)
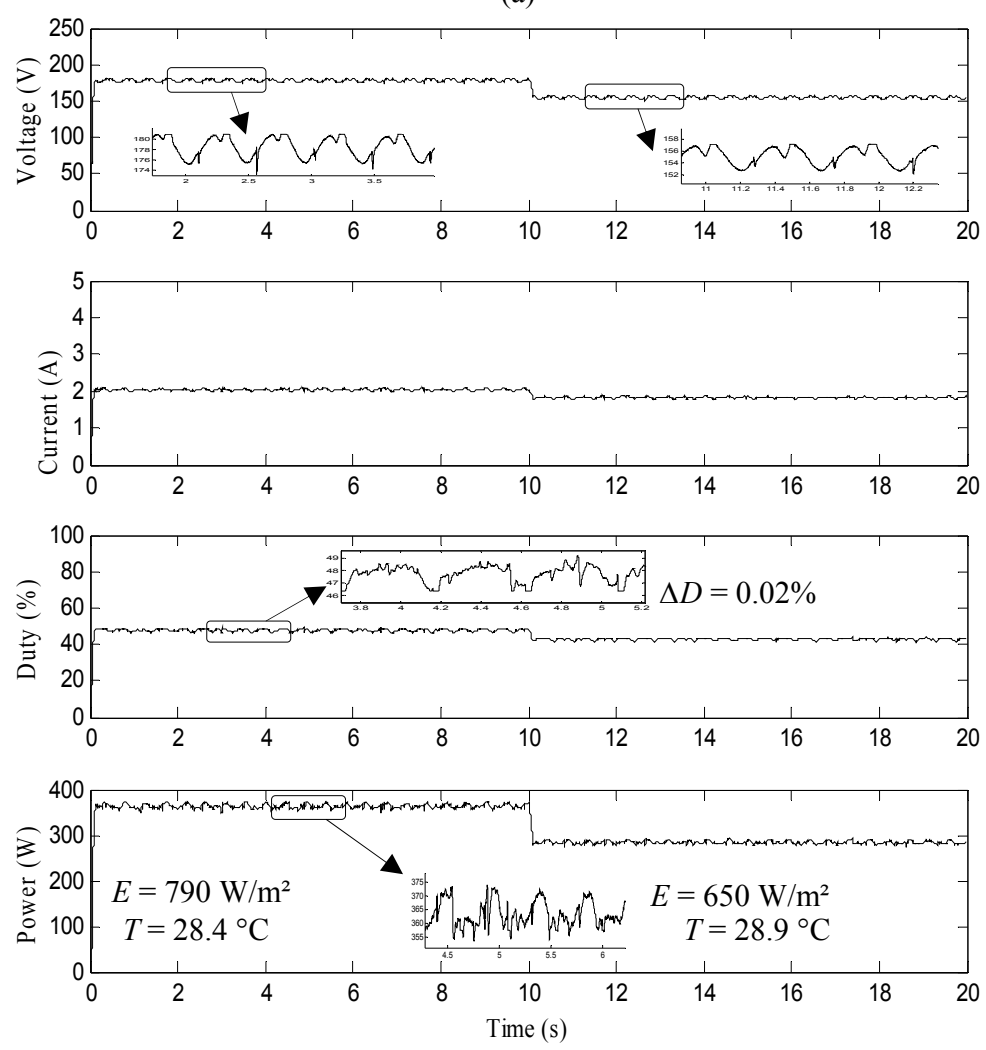

(b)

Fig. 15 PV-powered water pumping system response (voltage, current, duty cycle and power) under variable radiation and temperature: (a) simulation results and (b) experimental test results. 
The power response oscillates at the MPP. Its mean value is equal to $280 \mathrm{~W}$. At that point, the mean voltage and current are about $155 \mathrm{~V}$ and $1.8 \mathrm{~A}$, respectively.

All the results validate the relevance of the PV system.

\section{Conclusions}

This paper consists in designing, building and implementing a low-cost PV-powered water pumping system controlled by the P \& O MPPT technique. With this aim in mind, we have also successfully proposed an original operational model of this system and validate it experimentally.

Despite the fact that, ripples are present in the power and duty cycle waveform, the robustness of the model is verified both in modeling and experimental setup, which allows the machine to be invulnerable to electrical disturbances.

The $\mathrm{P} \& \mathrm{O}$ MPPT technique generates enough power to run the pumping water station under most low-light conditions. Moreover, the use of single phase induction motor allows obtaining a simplified, rugged and low cost system.

The proposed system could be very helpful in rural areas that which are not connected to the national grid.

\section{References}

[1] Mao, M., Jin, P., Chang, L., and Xu, H. 2014. "Economic Analysis and Optimal Design on Microgrids with SS-PVs for Industries." IEEE Transactions on Sustainable Energy 5 (4): 1328-36.

[2] Shadmand, M. B., Balog, R. S., and Johnson, M. D. 2014. "Predicting Variability of High-Penetration Photovoltaic Systems in a Community Microgrid by Analyzing High-Temporal Rate Data." IEEE Transactions on Sustainable Energy 4 (5): 1434-42.

[3] Varieras, R. V., Jusong, W., and King, D. L. 2013. "System Performance Considerations for Low-Concentration." IEEE Journal of Photovoltaics 3 (4): 1409-14.

[4] Singh, R., Alapatt, G. F., and Lakhtakia, A. 2013. "Making Solar Cells a Reality in Every Home: Opportunities and Challenges for Photovoltaic Device Design.” IEEE Journal of the Electron Devices Society 1
(6): 129-44.

[5] Jacques, S., Bissey, S., Ren, Z., and Caldeira, A. 2014. "PVLab, a Powerful, Innovative Software Package for the Simulation of Photovoltaic Systems." Journal of Energy and Power Engineering 8 (10): 1712-20.

[6] Nikhil, P. G., and Subhakar, D. 2013. "Sizing and Parametric Analysis of a Stand-Alone Photovoltaic Power Plant." IEEE Journal of Photovoltaics 3 (2): 776-84.

[7] Elgendy, M. A., Zahawi, B., and Atkinson, D. J. 2013. "Assessment of the Incremental Conductance Maximum Power Point Tracking Algorithm." IEEE Transactions on Sustainable Energy 4 (1): 108-17.

[8] Esram, T., and Chapman, P. L. 2007. "Comparison of Photovoltaic Array Maximum Power Point Tracking Techniques." IEEE Transactions on Energy Conversion 22 (2): 439-49.

[9] Subudhi, B., and Pradhan, R. 2013. "A Comparative Study on Maximum Power Point Tracking Techniques for Photovoltaic Power Systems." IEEE Transactions on Sustainable Energy 4 (1): 89-98.

[10] Reisi, A. R., Moradi, M. H., and Jamasb, S. 2013. "Classification and Comparison of Maximum Power Point Tracking Techniques for Photovoltaic System: A Review." Renewable Sustain. Energy Rev. 19 (C): 433-43.

[11] de Brito, M. A., Galotto, L., Sampaio, J. L. P., de Azevedoe Melo, G., and Canesin, C. A. 2013. "Evaluation of the Main MPPT Techniques for Photovoltaic Applications." IEEE Transactions on Industrial Electronics 60 (3): 1156-67.

[12] Hsieh, G. C., Hsieh, H. I., Tsai, C. Y., and Wang, C. H. 2013. "Photovoltaic Power-Increment-Aided Incremental-Conductance MPPT with Two-Phased Tracking." IEEE Transactions on Power Electronics 28 (6): 2895-911.

[13] Paz, F., and Ordonez, M. 2014. "Zero Oscillation and Irradiance Slope Tracking for Photovoltaic MPPT.” IEEE Transactions on Industrial Electronics 61 (11): 6138-47.

[14] Elgendy, M. A., Zahawi, B., and Atkinson, D. J. 2010. "Comparison of Directly Connected and Constant Voltage Controlled Photovoltaic Pumping Systems." IEEE Transactions on Sustainable Energy 1 (3): 21-33.

[15] Moballegh, S., and Jiang, J. 2014. "Modeling, Prediction, and Experimental Validations of Power Peaks of PV Arrays under Partial Shading Conditions." IEEE Transactions on Sustainable Energy 5 (1): 293-300.

[16] Chikh, A., and Chandra, A. 2015. "An Optimal Maximum Power Point Tracking Algorithm for PV Systems with Climatic Parameters Estimation." IEEE Transactions on Sustainable Energy 6 (2): 644-52.

[17] Aissou, S., Rekioua, D., Mezzai, N., Rekioua, T., and Bacha, S. 2015. "Modeling and Control of Hybrid Photovoltaic Wind Power System with Battery Storage." 
Energy Conversion and Management 89 (January): 615-25.

[18] Tey, K. S., and Mekhilef, S. 2015. “A Fast-Converging MPPT Technique for Photovoltaic System under Fast Varying Solar Irradiation and Load Resistance." IEEE Transactions on Industrial Informatics 11 (1): 176-86.

[19] Correa, M. B. R., Jacobina, C. B., Limax, A. M. N., and Silva, E. R. C. 2000. "Rotor-Flux-Oriented Control of Single-Phase Induction Motor Drive.” IEEE Transactions on Industrial Electronics 47 (4): 832-41.

[20] Alajmi, B. N., Ahmed, K. H., Adam, G. P., and Williams, B. W. 2013. "Single-Phase Single-Stage Transformer Less Grid-Connected PV System.” IEEE Transactions on Power Electronics 28 (6): 2664-76.

[21] Alajmi, B. N., Ahmed, K. H., Adam, G. P., and Williams, B. W. 2011. "Fuzzy-Logic-Control Approach of a Modified Hill-Climbing Method for Maximum Power Point in Microgrid Standalone Photovoltaic System." IEEE Transactions on Power Electronics 26 (4): 1022-30.

[22] Zahedi, B., and Vaez-Zadeh, S. 2009. "Efficiency Optimization Control of Single-Phase Induction Motor Drives." IEEE Transactions on Power Electronics 24 (4): 1062-71.

[23] Jemli, M., Azza, H. B., Boussak, M., and Gossa, M. 2009. "Sensorless Indirect Stator Orientation Speed Control for Single-Phase Induction Motor Drive." IEEE Transactions on Power Electronics 24 (6): 1618-27.

[24] Mademlis, C., Kioskeridis, I., and Theodoulidis, T. 2005. "Optimization of Single-Phase Induction Motors-Part I: Maximum Energy Efficiency Control." IEEE Transactions on Energy Conversion 22 (1): 187-95.

[25] Jang, D. 2013. "Problems Incurred in a Vector-Controlled SPIM, and a Proposal for a Vector-Controlled Two-Phase Induction Motor." IEEE Transactions on Power Electronics 28 (1): 526-36.

[26] Astorga, G. R., Torres, J. D. S., and Loukianov, A. G. 2014. "High-Order Sliding Mode Block Control of Single-Phase Induction Motor." IEEE Transactions on Control Systems Technology 22 (5): 1828-36.

[27] Ouchbel, T., Zouggar, S., Elhafyani, M. L., Seddik, M., Oukili, M., Aziz, A., and Kadda, F. Z. 2014. "Power Maximization of an Asynchronous Wind Turbine with a Variable Speed Feeding a Centrifugal Pump.” Energy Conversion and Management 78 (February): 976-984.

[28] Fiaschi, D., Graniglia, R., and Manfrida, G. 2005. "Improving the Effectiveness of Solar Pumping Systems by Using Modular Centrifugal Pumps with Variable Rotational Speed." Solar Energy 79 (3): 234-44.

[29] Jafarzadeh, B., Hajari, A., Alishahi, M. M., and Akbari, M. H. 2011. "The Flow Simulation of a Low-Specific-Speed High-Speed Centrifugal Pump." Applied Mathematical Modelling 35 (1): 242-9.

[30] Elgendy, M. A., Zahawi, B., and Atkinson, D. J. 2015.
"Operating Characteristics of the P \& O Algorithm at High Perturbation Frequencies for Standalone PV Systems." IEEE Transactions on Energy Conversion 30 (1): 189-98.

[31] Elgendy, M. A., Zahawi, B., and Atkinson, D. J. 2012. "Assessment of Perturb and Observe MPPT Algorithm Implementation Techniques for PV Pumping Applications." IEEE Transactions on Sustainable Energy 3 (1): 21-33.

[32] Kjaer, S. B. 2012. 'Evaluation of the 'Hill Climbing' and the Incremental Conductance' Maximum Power Point Trackers for Photovoltaic Power Systems." IEEE Transactions on Energy Conversion 27 (4): 922-9.

[33] Liu, F., Duan, S., Liu, F., Liu, B., and Kang, Y. 2008. "A Variable Step Size INC MPPT Method for PV Systems." IEEE Transactions on Industrial Electronics 55 (7): 2622-8.

[34] T-Fu, W., Chang, C., and Y-Kai, C. 2000. "A Fuzzy-Logic-Controlled Single-Stage Converter for PV-Powered Lighting System Applications." IEEE Transactions on Industrial Electronics 47 (2): 287-96.

[35] Al Nabulsi, A., and Dhaouadi, R. 2012. "Efficiency Optimization of a DSP-Based Standalone PV System Using Fuzzy Logic and Dual-MPPT Control." IEEE Transactions on Industrial Informatics 8 (3): 573-84.

[36] Alajmi, B. N., Ahmed, K. H., Finney, S. J., and Williams, B. W. 2013. "A Maximum Power Point Tracking Technique for Partially Shaded Photovoltaic Systems in Microgrids." IEEE Transactions on Industrial Electronics 60 (4): 1596-606.

[37] W-Min, L., C-Ming, H., and C-Hsing, C. 2011. "Neural-Network-Based MPPT Control of a Stand-Alone Hybrid Power Generation System." IEEE Transactions on Power Electronics 26 (12): 3571-81.

[38] Filho, F., Tolbert, L. M., Cao, Y., and Ozpineci, B. 2011. "Real-Time Selective Harmonic Minimization for Multilevel Inverters Connected to Solar Panels Using Artificial Neural Network Angle Generation.” IEEE Transactions on Industrial Applications 47 (5): 2117-24.

[39] Yang, H. T., Huang, C. M., Huang, Y. C., and Pai, Y. S. 2014. "A Weather-Based Hybrid Method for 1-Day Ahead Hourly Forecasting of PV Power Output." IEEE Transactions on Sustainable Energy 5 (3): 917-26.

[40] Bendib, B., Belmili, H., and Krim, F. 2015. "A Survey of the Most Used MPPT Methods: Conventional and Advanced Algorithms Applied for Photovoltaic Systems." Renewable and Sustainable Energy Reviews 45 (May): 637-48.

[41] Hohm, D. P., and Ropp, M. E. 2003. "Comparative Study of Maximum Power Point Tracking Algorithms." Progress in Photovoltaics: Research and Applications 11 (1): 47-62. 